\title{
Vascular reperfusion in pulmonary thromboembolism: certainties and uncertainties
}

\author{
Veronica Moreira Amado1,a
}

Pulmonary thromboembolism (PTE) is the leading cause of death in patients with venous thromboembolism. Between 2001 and 2009, the incidence of PTE increased from 29 to 78 cases per year; this increase is partly due to an increase in the number and quality of imaging tests, particularly chest CT angiography, as well as to incidental findings of pulmonary embolism on routine examinations for other diseases, such as cancer. ${ }^{(1,2)}$ Despite technological advances, the diagnosis of PTE remains a challenge; autopsy studies have shown that the prevalence of PTE cases undiagnosed in life is $84.6 \%$. $^{(3)}$

In patients with PTE, pulmonary vascular obstruction and the consequent increase in pulmonary vascular resistance result in a sudden increase in right ventricular (RV) afterload. The increase in RV afterload is primarily dependent on the magnitude of the embolic load and on the extent to which the pulmonary circulation can use adaptation mechanisms such as vascular recruitment and distension in order to compensate for the obstruction. Previous cardiovascular conditions play a role in the extent to which the right ventricle can adapt to the increase in afterload. Acute RV failure is a marker of pulmonary embolism severity, given that reduced cardiac output can result in hemodynamic instability and, eventually, death. ${ }^{(4,5)}$

In low-risk and low intermediate-risk patients, the treatment of PTE consists of anticoagulation; given that RV function is preserved in such patients, there is no urgent need to clear the obstructed vascular bed. Oral anticoagulants with direct anti-factor $\mathrm{Xa}$ and antithrombin activity constitute an alternative to conventional treatment with anti-vitamin $\mathrm{K}$ anticoagulants, the effects of which should be monitored periodically; in addition, anti-vitamin $\mathrm{K}$ anticoagulants have high drug-drug and food-drug interaction potential. ${ }^{(5,6)}$

The need for rapid clearance of the pulmonary vascular bed in patients with PTE and hemodynamic instability is well established in the literature, thrombolytic therapy being the treatment of choice in such cases. ${ }^{(5,7)}$ However, there is controversy in the literature regarding the use of thrombolytics in patients with RV dysfunction without hemodynamic instability and with a high intermediate risk of death. ${ }^{(8,9)}$ Treatment with thrombolytics has been found to have no beneficial effects on mortality in such patients, despite the fact that reperfusion occurs more rapidly; there is an increased risk of severe bleeding, intracranial bleeding occurring in $2 \% .{ }^{(8)}$ For years, attempts were made to identify a subgroup of patients at an increased risk of hemodynamic instability and benefiting from thrombolysis as initial therapy despite the risk of bleeding. Despite the use of algorithms employing biomarkers and imaging tests to assess RV function, no such subgroup was identified. ${ }^{(10)}$ Therefore, in high intermediate-risk patients, thrombolysis should be prescribed on a case-by-case basis, depending on the clinical setting and on patient progression. In recent years, it has been proposed that expert panels be convened in order to discuss high-risk and high intermediate-risk PTE cases and make decisions regarding treatment optimization. ${ }^{(11)}$

In the current issue of the JBP, there is a good review of indications for reperfusion, as well as reperfusion modalities, in patients with PTE. (12) Conventional thrombolysis remains the most widely used drug therapy for achieving reperfusion. However, treatment options such as low-dose, peripherally administered thrombolytic therapy or in situ thrombolysis to reduce the risk of bleeding have shown good results; nevertheless, further studies are needed in order to define their therapeutic role. Invasive approaches such as surgical embolectomy and catheter-based embolectomy have gained prominence in recent years, having been used primarily in patients with hemodynamic instability (in whom thrombolytics are contraindicated) but also in those receiving thrombolytic therapy and requiring rescue therapy for failed reperfusion.

The diagnosis and treatment of PTE remain challenging. Nevertheless, recent advances in treatment options have contributed to improving the prognosis of patients with PTE.

\section{REFERENCES}

Heit JA Epidemiology of venous thromboembolism. Nat Rev Cardio 2015;12(8):464-74. https://doi.org/10.1038/nrcardio.2015.83

2. Ferreira EV, Gazzana MB, Sarmento MB, Guazzelli PA, Hoffmeister $\mathrm{MC}$, Guerra VA, et al. Alternative diagnoses based on CT angiography of the chest in patients with suspected pulmonary thromboembolism J Bras Pneumol. 2016;42(1):35-41. https://doi.org/10.1590/S180637562016000000105

3. Yoo HH, Mendes FG, Alem CE, Fabro AT, Corrente JE, Queluz TT. Clinicopathological findings in pulmonary thromboembolism: a 24-year autopsy study. J Bras Pneumol. 2004;30(5):426-32.

4. Laporte S, Mismetti P, Décousus H, Uresandi F, Otero R, Lobo JL, et al. Clinical predictors for fatal pulmonary embolism in 15,520 patients with venous thromboembolism: findings from the Registro Informatizado de la Enfermedad TromboEmbolica venosa (RIETE) Registry. Circulation. 2008;117(13):1711-6. https://doi.org/10.1161/ CIRCULATIONAHA.107.726232

5. Konstantinides SV, Torbicki A, Agnelli G, Danchin N, Fitzmaurice D, Galiè N, et al. 2014 ESC Guidelines on the diagnosis and management of acute pulmonary embolism. Eur Heart J. 2014;35(43):3033-69, 3069a-3069k.

6. Fernandes CJ, Alves Junior JL, Gavilanes F, Prada LF, Morinaga LK, Souza R. New anticoagulants for the treatment of venous 
thromboembolism. J Bras Pneumol. 2016;42(2):146-54. https://doi org/10.1590/S1806-37562016042020068

7. Stein PD, Matta F. Thrombolytic therapy in unstable patients with acute pulmonary embolism: saves lives but underused. Am J Med. 2012;125(5):465-70. https://doi.org/10.1016/j.amjmed.2011.10.015

8. Meyer G, Vicaut E, Danays T, Agnelli G, Becattini C, BeyerWestendorf $\mathrm{J}$, et al. Fibrinolysis for patients with intermediate-risk pulmonary embolism. N Engl J Med. 2014;370(15):1402-11. https:// doi.org/10.1056/NEJMoa1302097

9. Goldhaber SZ. PEITHO Long-Term Outcomes Study: Data Disrupt Dogma. J Am Coll Cardiol. 2017;69(12):1545-1548. https://doi. org/10.1016/j.jacc.2017.01.027
10. Kostrubiec M, Pruszczyk P, Bochowicz A, Pacho R, Szulc M, Kaczynska A, et al. Biomarker-based risk assessment model in acute pulmonary embolism. Eur Heart J. 2005;26(20):2166-72. https://doi. org/10.1093/eurhearti/ehi336

11. Kabrhel C, Rosovsky R, Channick R, Jaff MR, Weinberg I, Sundt T, et al. A Multidisciplinary Pulmonary Embolism Response Team: Initial 30-Month Experience With a Novel Approach to Delivery of Care to Patients With Submassive and Massive Pulmonary Embolism. Chest. 2016;150(2):384-93. https://doi.org/10.1016/j.chest.2016.03.011

12. Fernandes CJCS, Jardim CVP, Alver JL Jr, Oleas FAG, Morinaga LTK Souza R. Reperfusion in acute pulmonary thromboembolism. J Bras Pulmonol. 2018;44(3):237-243. 